\title{
UK PhD Assessment in Accounting and Finance: Social Capital in Action
}

\section{Sarah Jane Smith and Vivien Urquhart}

September 2017

\author{
Sarah Jane Smith (corresponding author) \\ Reader in Accounting \\ Stirling Management School \\ University of Stirling \\ Stirling \\ FK9 4LA \\ Tel. +44(0)1786 467299 \\ Emailsarah.smith@stir.ac.uk \\ Vivien Urquhart (previously Vivien Beattie) \\ Formerly Distinguished Professor of Accounting (now retired) \\ Lancaster University Management School, \\ Lancaster University \\ Lancaster \\ LA1 4YX \\ Tel. $=447789281074$ \\ Email vivienannurquhart@ gmail.com
}

\section{Acknowledgments:}

We would like to thank The Scottish Accountancy Trust for Education and Research for funding the research upon which this paper is based. Particular thanks go to the academic members of staff and recently graduated $\mathrm{PhD}$ students for their participation in this study. We would also express our gratitude to the anonymous reviewers and associate editor who provided very useful comments on earlier drafts of this paper. 


\title{
UK PhD Assessment in Accounting and Finance: Social Capital in Action
}

\begin{abstract}
Assessment lies at the centre of $\mathrm{PhD}$ degree quality standards (Clarke, 2013), with quality assurance relying on independent external examiners. This study investigates the role of the viva and the selection of external examiners from within the accounting and finance discipline across UK institutions. A questionnaire survey and follow-up interviews with academics (299 respondents; 49 interviews) and recent $\mathrm{PhD}$ graduates (73 respondents; 18 interviews) is undertaken. Findings identify multiple viva roles including: verification; academic career development; and assessment. External examiner selection is outcome-driven, and the independence of examiners is questionable when secured using the social capital existing between examiner and supervisor. Supervisors and examiners jointly gate-keep the academic community within cliques, although at the viva stage new entrants are rarely excluded. The $\mathrm{PhD}$ assessment process offers the opportunity for rogue cliques to develop, driven by favourable outcomes in terms of personal benefits and costs, allowing new entrants of insufficient quality.
\end{abstract}

Keywords: UK, Accounting \& Finance, PhD Assessment, Social Capital 


\section{Introduction}

The purpose of the present paper is to investigate both the role of the viva in the $\mathrm{PhD}$ assessment process, and the selection of external examiners, using survey and interview evidence obtained across the UK accounting and finance academic community. Assessment lies at the centre of $\mathrm{PhD}$ degree quality standards (Clarke, 2013), with an assurance of consistency in quality standards across the academy being the intended function of independent external examiners. The present paper questions the notion of independence through the use of social capital theory, considers whether the $\mathrm{PhD}$ assessment process is consistent across the academy, and identifies potential implications for quality assurance.

The UK has witnessed a rapid increase in $\mathrm{PhD}$ student numbers across many disciplines in recent years. According to the Higher Education Statistics Agency (HESA), the number of doctorates awarded across all disciplines in UK institutions in 2015/2016 amounted to 23,345 compared to 14,875 in 2003 (Green, 2008). This increase in numbers is one of the factors which has led the $\mathrm{UK} \mathrm{PhD}$ to come under scrutiny by the government, higher education sector organisations, and funding bodies (Clarke, 2013). Quality assurance mechanisms and consistency of standards are imperative in terms of benchmarking the UK doctorate in today's global higher education environment (QAA, 2015). Quality assurance is important for the future of the global academic labour market, given that the award of the $\mathrm{PhD}$ qualification is increasingly required as a pre-requisite for the appointment of new faculty to research-active contracts. The supervision of successful $\mathrm{PhD}$ completions is also becoming a key pre-requisite for existing faculty pursuing promoted posts. Successful completions are employed as a key performance indicator at the institutional level (Morley, Leonard \& David, 2002; 2003) and PhD student numbers have been collated as part of the academic environment in the UK Research Excellence Framework (REF) submission. The potential pressure, on both individual academics and institutions, across disciplines in the $\mathrm{UK}$, for successful $\mathrm{PhD}$ completions in significant numbers, is evident.

Integral to the $\mathrm{PhD}$ qualification awarded by universities in many countries, including the UK, is the notion of peer review involving the participation of an external 
examiner, and via a defence mechanism in the form of a viva (Powell and Green (2007). On this basis, PhD assessment and external examiner selection are of potential interest to an international audience. Whereas in many countries this defence mechanism is public, in the UK the viva is usually a 'closed' examination, between the candidate and examiners, with the supervisor permitted to observe if the candidate and examiners give permission (QAA, 2014). The outcome of the viva is the award (or not) of the PhD qualification. According to Morley et al. (2003), the viva is a central site of power, having a major gatekeeping function in terms of entry to and exclusion from academia. Khalifa and Quattrone (2008) identify gatekeepers as key to the political and ethical functioning of academic practices and, ultimately, to knowledge creation. However, it has been suggested that the viva is surrounded by uneven power relationships with multiple agendas at work (Park, 2003). Whilst the outcome of the viva is, in theory, in the hands of both internal and external examiners, identifying and securing these potential examiners falls within the remit of the $\mathrm{PhD}$ supervisor. Green (2008) notes the existence of 'considerable anecdotal evidence of the inadequacies of the process and the power of external examiners' (p.60). Despite the fact that there are chapters on research degrees (B11) and external examining (B7) in the UK Quality Code for Higher Education (QAA, 2011), the characteristics of who can supervise is not regulated at a national level in the UK (Powell and Green, 2007). This is also the case in terms of who can examine. Institutions appear to operate varying guidelines on external examiner appointments which in practice often results in minimal constraints. According to Gibney (2013), the viva in the UK is not conducted to any national policy standard.

The external examiner system in the UK, like many countries, relies on 'policing itself' (Hannan and Silver, 2006) and the $\mathrm{PhD}$ assessment process relies on the academic community's ability to informally encourage cooperation to act as external examiners. Cooperative behaviour and informal favour exchange within networks or groups is the focus of the literature on social capital (Jackson, Rodriguez-Barraquer \& Tan, 2012).

Social capital refers to social connections and the associated norms and trust expected across those connections (Putnam, 1995). Social capital involves cooperation between individuals ultimately pursuing their own self interests, including the expectation of reciprocity, and can be a benefit not just to the individuals involved but all who are 
part of the relevant social group (Colman, 1988), which in the present context is the academic community. In the absence of formal enforcement, external examiner procurement and the viva process both rely on social capital to function. However, the underlying assumption of external examining is independence, and independence is questionable if social capital is used to secure an examiner and agreement to act is based on informal favour exchange. Further, social capital is not without negative consequences (Field, 2010). Individuals are naturally inclined to pursue self-interests which may not always be in the best interests of the community (Barash, 2003); and with the ascendance of corporate culture into academia, comes the realisation that academics can enhance their own social capital at the expense of the common good (Twale and De Luca, 2008). In this respect, examiners could be procured on the basis of a favourable $\mathrm{PhD}$ outcome, rather than in the interests of an independent assessment of quality standards. According to Bourdieu (1986), the benefits derived from social capital are unequally distributed, serving as a means to enhance inequality by increasing the status and privilege of those well connected - articulated by Field (2010) as 'a superior form of mutual back-scratching and self-advancement' (p.84). In the present context, examiners could be procured on the basis of their similarities in calibre to supervisors, resulting in academic community segregation and a lack of quality assurance across all dimensions of the population.

Research evidence in respect of the UK viva in general is relatively sparse (Jackson \& Tinkler, 2001) and certainly does not reflect the importance of the viva occasion (Wellington, 2010). From the studies available, a lack of consensus regarding the role of the viva and its significance in the $\mathrm{PhD}$ assessment process is apparent. These prior studies (for example: Crossouard, 2011; Jackson \& Tinkler, 2001; Phillips, 1994) mainly investigate such issues using samples of subjects representing a range of different disciplines, rather than from within one particular discipline. They were also conducted before increased attention was given to the regulatory framework for research degrees in the UK. The UK Quality Code for Higher Education makes it clear that a $\mathrm{PhD}$ candidate is assessed on both an appropriate body of work (the thesis) and the viva (Chapter B11, QAA, 2011). However, there is no further indication provided of the weighting which should be attached to each element. If the role of the viva in the overall assessment is unclear, then the responsibility for the potential gatekeeping function is also unclear. If the award of a $\mathrm{PhD}$ lies mainly with 
the written thesis and the viva is substantially ceremonial, then the supervisor has significant opportunity to influence the outcome and take on the gatekeeping function. If the viva is the pivot of the $\mathrm{PhD}$ assessment process, the supervisor still has influence arising through the selection of examiners. The significance of the gatekeeping function is potentially different across disciplines (Whitley, 1984), as is the degree of pressure relating to the volume of successful $\mathrm{PhD}$ completions.

The contribution of the present study is to investigate both the role of the viva in the $\mathrm{PhD}$ assessment process, and the selection of external examiners within the UK accounting and finance disciplines. The two disciplines are considered jointly as they often co-exist in a single academic unit in UK institutions. The existence of the British Accounting and Finance Association (BAFA), which serves to promote closer relationships between UK accounting and finance academics, is indicative of a closeknit community. Further, institutional pressure to take on a significant number of $\mathrm{PhD}$ students and ensure timely completion by these accounting and finance academic units has previously been documented (Beattie and Smith, 2012). However, the PhD assessment process within the UK accounting and finance disciplines does not appear to have been previously investigated. Accounting and finance are key business school disciplines making a substantial financial contribution across institutions (Parker \& Guthrie, 2010). Based on 2012 data, Accounting and finance is taught across 102 higher education institutions in the UK, employing 1726 members of academic staff (Smith \& Urquhart, 2016). A precise quantification of accounting and finance $\mathrm{PhD}$ student numbers across UK institutions is not available. However, Beattie \& Smith (2012) offer a conservative estimate of 1008 current $\mathrm{PhD}$ students in 2011. In reality, numbers were expected to be higher as a number of institutions failed to disclose relevant data. Given the volume of $\mathrm{PhD}$ student numbers, in the accounting \& finance disciplines, it has been suggested that quality is compromised for quantity in some circumstances (Smith \& Urquhart, 2016). They provide evidence to suggest that UK accounting and finance $\mathrm{PhD}$ programmes are not providing candidates of sufficient quality to meet the current recruitment needs of the academic community. Of 200 new lecturers appointed in accounting and finance in the two-year period between 2010 and 2012 across UK institutions, only 74 came from UK accounting and finance $\mathrm{PhD}$ programmes. Quality assurance is a key concern when a significant number of academics have recently expressed the opinion that the standard required for the 
award of PhD in accounting and finance has declined (Beattie \& Smith, 2012). The present study considers whether the $\mathrm{PhD}$ assessment process is consistent across the academy and the potential implications for quality assurance if the procurement of independent external examiners relies on the existence of social capital. Findings are based on a questionnaire survey and follow up interviews with academics (229 respondents; 49 interviews) and recently graduated $\mathrm{PhD}$ students (73 respondents; 18 interviews) The present study responds to Khalifa \& Quattrone's (2008) proclamation, made in the context of the governance of accounting academia: 'only by knowing more, can we provide more adequate solutions for better governance' (p.76).

\section{Social capital and the supervision and examination of PhDs}

A successful $\mathrm{PhD}$ completion relies on both the ability to appoint external examiners and a positive assessment made by those examiners as part of the viva process. There is no formal requirement on academic staff to act as an external examiner. Hanan and Silver (2006), in the undergraduate context, found that UK institutions typically neither directly encourage nor discourage their academic staff to take on such discretionary roles. The viva process would, therefore, appear to rely on the academic community's ability to informally encourage cooperation to act as external examiners. This notion has been raised previously by Hanan and Silver (2006) in terms of the external examining system relying on 'professional commitment to what the system represents' (p.62). Further, Morley et al. (2002) argue that $\mathrm{PhD}$ examination is left to 'informal networks and a belief in a notion of collegiality' (p.270). However, these previous researchers do not appear to theoretically develop this observation and go on to identify that the $\mathrm{PhD}$ assessment process appears to rely on the creation and execution of social capital, i.e. to provide an example of social capital in action.

Social capital represents the ability of a society to foster trust and cooperation among its members (Jackson et al., 2012). This cooperation, according to Coleman (1988), should go beyond one academic to another, to extend to a network of academics whose relationships are governed by a high degree of trust and shared values. Cooperation in the form of acting as an external examiner comes at an individual cost in terms of time away from pursuing other academic activities. However, it is not a 
selfless act when it brings tangible benefits, including potential reciprocity and intelligence gathering (Hanan \& Silver, 2006). According to Homans (1958), social capital involves not only an exchange of tangible benefits but also intangible ones, such as 'the symbols of approval or prestige' (p.606). Further, it is in the interest of individuals to cooperate given '(credible) threats of ostracism or loss of multiple relationships for failure to behave well' (Jackson, et al., 2012, p.1858). Bloxham, Hudson, den Outer \& Price (2015) found some evidence that external examiners, in general, may be prohibited from giving negative appraisals for fear of the impact on future relationships and employment prospects. If securing external examiners and the potential behaviour of those examiners is based on the existence and maintenance of social capital, the $\mathrm{PhD}$ assessment process is potentially questionable, given the underlying assumption is of an independent peer review.

The corporate culture, which currently dominates academia, potentially incentivises individual academics to enhance their own social capital at the expense of the common good (Twale \& De Luca, 2008). In such a climate, individual social capital benefits may often take precedence over independent quality assurance assessment. Further, Bourdieu (1986) views social capital as the exclusive property of the elites, created during the process of securing their relative position at the top of the hierarchy. In the context of academia, new entrants are unlikely to exhibit the same authority as established names when it comes to encouraging external examiner cooperation. Indeed, when gatekeeping is in operation, those occupying such roles tend to be the most distinguished academics, 'the stars' of a particular discipline (Cole, 1983).

In the context of $\mathrm{PhD}$ assessment and quality assurance, social capital appears to require a homogenous population given the pre-requisite of trust and shared values. Shared values in terms of $\mathrm{PhD}$ assessment is necessary to ensure comparability and maintenance of quality standards. However, academia in the UK cannot be said to comprise a homogenous population when rankings of individual institutions, and academics within them, exist at every turn. Ranking profiles result in situations where members of a population interact directly with many other members but with varying degrees of intensity (Feinberg \& Kets, 2014); and perceived or actual heterogeneity can preclude cooperation across the population resulting in the creation of several homogenous sub-groups and cooperation within cliques (Haag \& Lagunoff, 2006). 
Less competent individuals approach more competent individuals for cooperation less frequently because of the high costs of repeated admissions of inferiority (Homans, 1958). Indeed, in the undergraduate context, Bloxham \& Price (2015) find comparability of standards to exist within fairly narrow parameters. If $\mathrm{PhD}$ supervision and assessment were to occur only between academics of similar calibre / academic standing, within population sub-groups or cliques, then quality assurance and consistent standards across the entire UK accounting and finance academic community is unlikely to be achieved.

\section{Prior empirical investigations of the role of the viva and external examiner selection}

The viva process within the UK accounting and finance discipline does not appear to have been previously investigated. Of the few UK studies identified across a range of disciplines, questionnaire surveys, interviews, and focus groups have been used to elicit the views and opinions of relatively small samples of respondents. In the main, prior studies either focus exclusively on the student perspective (Wallace, 2003; Wellington, 2010; Crossouard, 2011) or consider the perspectives across a range of students, supervisors, and/or examiners (Phillips, 1994; Jackson \& Tinkler, 2001; Denicolo, 2003; Loumansky \& Jackson, 2004).

Of specific relevance to the present study, Crossouard (2011) conducted twenty semistructured interviews across eight English universities with $\mathrm{PhD}$ graduates in a range of disciplines. Findings indicate that the viva does appear to have genuine assessment implications. However, there is reason to be concerned in terms of the subjectivity involved and to question why the viva continues to be used. Phillips (1994) interviewed 41 students and 58 academics from four UK institutions with the purpose of examining quality in the $\mathrm{PhD}$ process. In relation to the viva, the process of selection of external examiner, including student involvement, was found to be variable. Jackson \& Tinkler (2001) considered institutional policy data from 20 UK universities, combined with questionnaire data from lecturers and previous $\mathrm{PhD}$ students at two universities in 1999 across arts, humanities and social science departments. Findings indicate a lack of consensus regarding the role of the viva in the $\mathrm{PhD}$ examination process, and considerable diversity in relation to the significance 
of the viva in overall assessment. Denicolo (2003) obtained 62 responses from a questionnaire survey of current staff, current students, and students who had completed in the last four years in a UK faculty of education. Findings indicated that, although the viva was important, the thesis was given priority in terms of assessment. However, confusion and diversity of opinion was evident across respondents. A decline in the supply of examiners in the sector was apparent as experienced examiners were retiring and younger colleagues were becoming increasingly reluctant to engage in a demanding, time-consuming activity associated with little appreciation in any form. Loumansky \& Jackson (2004) conducted a pilot study of 17 questionnaires distributed at a UK women's studies conference in 2003 and online responses from women about to have their viva or who had recently had their viva, supervisors / examiners. They report a lack of consistency in practice across universities and that 'choices of examiners are often determined via an 'old boys' network and are at times haphazard' (p.23). They concluded that the closed-door approach to the viva in the UK provides a safe haven for inequalities.

There are studies of some relevance to the present study which have considered $\mathrm{PhD}$ assessment outside of the UK. Kyvik (2014) considered the PhD assessment system in Norway from the viewpoint of examiners from the USA, UK and Sweden. In comparing different systems of assessment, Kyvik notes that in the UK, unlike Norway and Sweden, the viva procedure is aligned towards enhancing the quality of the thesis by providing the opportunity to require minor amendments or larger revisions post-viva. However, the private nature of the viva in the UK is criticised for its lack of transparency. The viva in the UK has the potential for final assessment decision-making, whereas 'the viva as a site of final decision-making in borderline cases has practically no role in the Norwegian and Swedish examination [public defence] systems' (Kyvik, 2014, p. 152). Breimer and Nilsson (2014) surveyed 170 Swedish mentors of $\mathrm{PhD}$ candidates in the biomedical sciences. It was found that $\mathrm{PhD}$ examiners external to the country were preferable in terms of their expertise in the research field and to avoid conflict of interests across national academics. Career path facilitation in terms of post-doc job opportunities and research collaborations were also found to be a consideration. Casanueva \& Larrinaga (2013) use social network analysis to examine the selection of members of accounting $\mathrm{PhD}$ panels in Spain. Araujo (2005) interviewed Portuguese university lecturers preparing for their 
doctorate degree between 2001 and 2003. In Portugal, the presentation and assessment of the $\mathrm{PhD}$ (viva) lasts three hours during which candidates have to answer questions posed by five professors including their supervisor. This assessment was considered the most important critical date of the PhD process. Carter (2008) investigates experiences of 23 faculty members across disciplines in New Zealand in their capacity as oral examiner by conducting informal panel discussions before audiences of doctoral students. A sense of duty and the hopes of reciprocation motivated acceptance to act as examiner. However, examiners were divided in terms of the assessment function of the viva. One school of thought was that the thesis forms the basis for assessment and the viva was entirely benign, whereas the other clearly saw the viva as an examination which impacts the outcome of the $\mathrm{PhD}$. The viva enabled examiners to clarify that it was the student's own work, and make sure students understood their thesis. Most oral examinations were found to take between one and a half to two hours.

In summary, prior research, mainly focusing across disciplines, highlights a lack of consensus regarding the role of the viva and its significance in the $\mathrm{PhD}$ assessment process. Further, there appears to be a lack of insight with regard to issues such as the behaviour, selection, and supply of external examiners. The specific research questions addressed in the present paper are as follows: (i) Are external examiners in the $\mathrm{PhD}$ process independent if they are procured using the supervisor's social capital? (ii) Is the $\mathrm{PhD}$ assessment process consistent across the academy thus providing quality assurance?

To address these research questions, the present paper investigates the viva experience and related views and opinions of recently graduated $\mathrm{PhD}$ students and academic staff from within one discipline, accounting and finance. In particular, the role of the viva in the $\mathrm{PhD}$ assessment process is considered, given that a shared understanding of the role would appear necessary in providing consistency, and thus quality assurance, across the academy. Responsibility for, and the selection of, $\mathrm{PhD}$ examiners is also considered from the perspectives of both independence and consistency in practice. The existence of any pressures in relation to $\mathrm{PhD}$ outcomes are also investigated given the potential implications for quality assurance. 


\section{Methods}

\section{Questionnaire design and administration}

Questionnaire responses were collected as part of a survey investigating all aspects of the $\mathrm{PhD}$ process. The online survey software and questionnaire tool SurveyMonkey was used for electronic distribution in May / June 2011. Piloting, personally addressed emails by institution, anonymous responses and reminder mailings were all used to enhance the response rate, along with the inclusion of an incentive to either enter a prize draw to win an Ipad or charity donation. Interview participants were secured via a link independent from questionnaire responses.

\section{Sample and survey response}

A database of recently graduated PhD students (2006 onwards) was pieced together using alumni information displayed at the time of the study on the web sites of each UK university. Data was also available from web searches undertaken three or four years earlier on current students of the time. An attempt to locate contact details was made via general internet searches. For recently graduated $\mathrm{PhD}$ students working in UK institutions, contact details were available from a database of current UK academic staff. This was constructed by comparing the details provided in The British Accounting Review Research Register 2010, which documents all UK accounting and finance academics, with staff profile web pages. In total, 251 and 1400 valid email addresses were obtained for the purposes of distributing the questionnaire survey to recently graduated students and academic staff. In total, 73 responses were received from recently graduated $\mathrm{PhD}$ students giving a response rate of $29 \%$. For academic staff, 299 responses were received giving a response rate of $21 \%$. Of the 299 academics who responded, $65 \%$ were male and $35 \%$ were female. With respect to institution type, the number of UK universities significantly increased when university status was awarded to former polytechnic institutions in 1992. These new post-1992 institutions are typically characterised as less-research focused institutions, compared to the older, more research focused, pre-1992 institutions. It might, therefore, be expected that $\mathrm{PhD}$ supervision / examining is more concentrated in pre1992 institutions. Indeed, the majority of questionnaire responses, 65\%, were received by academics employed by pre-1992 institutions. However, approximately $86 \%$ from pre-1992 institutions and 62\% from post-1992 institutions had $\mathrm{PhD}$ supervision experience. The length of employment as academic members of staff 
across UK institutions was, on average, 16.2 years. Approximately $30 \%$ were currently full professors. Of the 73 recently graduated $\mathrm{PhD}$ students, $68 \%$ were male and $32 \%$ were female. The vast majority (90\%) had graduated with their $\mathrm{PhD}$ from pre-1992 institutions.

\section{Interview methods and interviewees' profile}

During the period October 2011 to December 2011, 18 interviews of recently graduated $\mathrm{PhD}$ students and 49 interviews of academics were conducted. Of the 67 interviews conducted, 31 were face-to-face and 36 were by the telephone. All interviews were tape recorded and subsequently transcribed. Individual interviewees cited have been consecutively numbered to demonstrate that interview quotes used have been taken from a cross-section of participants, their title and institution type are also provided.

\section{Findings}

Survey and interview evidence is presented in sub-sections as follows: multiple and potentially conflicting roles of the viva; responsibility for the selection of $\mathrm{PhD}$ examiners; external examiner selection; and pressure in relation to $\mathrm{PhD}$ outcomes.

\section{Multiple and potentially conflicting roles of the viva}

\section{Gatekeeping role}

The viva does not appear to be used to significantly deter new membership to the academic community, since the vast majority of vivas eventually result in the award of $\mathrm{PhD}$. Across academic survey respondents, there were only 22 incidents where a $\mathrm{PhD}$ was not awarded (i.e. no opportunity given for corrections or resubmission). By way of comparison, 241 vivas were identified where the $\mathrm{PhD}$ was awarded without any corrections and 399 occasions where resubmission was required. Further, approximately $86 \%$ of recently graduated students indicated that the outcome of their viva was the award of $\mathrm{PhD}$ subject to either no corrections (19\%) or minor corrections to the satisfaction of the internal examiner (67\%). Approximately $10 \%$ were awarded the degree with corrections which had to meet the satisfaction of the external examiner. Only $4 \%$ were not awarded the degree as an outcome to the viva, requiring 
major corrections and resubmission. The duration of the viva provides an indication of the significance attached to such occasion. The duration of the viva experienced by recently graduated $\mathrm{PhD}$ students responding to the questionnaire survey was, on average, 2.03 hours. However, a standard deviation of 0.83 hours indicated significant variation, with a minimum duration of half an hour compared to a maximum of four hours.

\section{Verification role}

From interviews with academics, the most frequently cited purpose of the viva was verification that the $\mathrm{PhD}$ students had actually undertaken the work themselves. Whilst the issue of plagiarism was obviously a concern, the primary concern appeared to be the inappropriate contribution made by the supervisor. Pressures on academic staff, in terms of both $\mathrm{PhD}$ completions and publishing joint academic papers, were identified as motivations for substantial supervisor involvement: 'First of all, it is to make sure that the work is the student's own work. Particularly when you have staff who are really under pressure to get PhD completions'. [29, Professor, Pre-1992]. 'It [the viva] identifies it isn't just something dictated to them by their supervisor who wanted to get lots of joint papers out of them'. [16, Professor, Pre-1992]. The use of the viva for authenticating $\mathrm{PhD}$ student's work appears to support the gatekeeping function (Morley et al., 2003). As one interviewee put it: 'It is ritualistic and very tough mechanism, by which is decided whether or not you're allowed to join the club' [7, Professor, Pre-1992]. Evidence to substantiate a verification role appears to support the notion of an independent peer review and thus provide quality assurance.

\section{Early career development role}

Several academics were of the view that the viva served a function beyond the outcome of the $\mathrm{PhD}$ in terms of assisting in early academic career development: 'The main purpose is to give students feedback, independent feedback on how they can develop their work and how they can actually make it publishable' [40, Professor, Pre-1992]. Publication advice also appeared to be an expectation of recently graduated $\mathrm{PhD}$ students, though it was not always forthcoming: 'I expected more from the viva. I wanted them to really give me a guide, for example, what kind of journals 
to publish the work, or where to strengthen areas, and things like that, and they didn't provide that kind of evaluation.' [31, Recently Graduated, Pre-1992]

\section{Role in PhD assessment process}

Prior cross-disciplinary research has identified considerable diversity in relation to the significance of the viva in the $\mathrm{PhD}$ assessment process (Jackson \& Tinkler, 2001). The viva has been found to have genuine assessment implications in some studies (Crossouard, 2011), whereas in others the thesis appears to be given priority (Denicolo, 2003). However, these studies were mainly conducted before increased attention was given to the regulatory framework for research degrees in the UK. The UK Quality Code for Higher Education has subsequently made it clear that $\mathrm{PhD}$ assessment is based on both an appropriate body of work (the thesis) and the viva (Chapter B11, QAA, 2011). Further, in 2014, the European Institute for Advanced Studies in Management (EIASM) and the European Doctoral Association in Management and Business Administration (EDAMBA) published a European Code of Practice for Doctoral Studies in Management and Business (which captures accounting and finance). The basic standard identified was that peer judgement should be based on both the thesis and the oral defence.

From the interviews in the present study, it was apparent that several academics saw the thesis as the primary focus for assessment: 'It is in the reading of the thesis I think' [23, Professor, Pre-1992]. 'My view is that the thesis stands and falls as a thesis' [32, Professor, Post-1992]. '90\% of the time these days the outcome is more or less decided by the thesis and conferring by the examiners prior to the examination taking place' [38, Professor, Post-1992 institution]. Many students also adopted the same perspective: 'I don't think it [the viva] really plays that much of a role, if I'm frank. I wouldn't say it's a tick box but at the same time I know the examiners have a report that they have to write even before the viva, anyway, in terms of outcome'. [33, Recently Graduated, Pre-1992]. 'The viva it was just some sort of ceremony. It wasn't really probing into the work. Ticking the box and going through the motions of a viva'. [34, Recently Graduated PhD Student, Pre-1992].

The behaviour of a number of external examiners, in terms of communicating the outcome to the student beforehand, appears to suggest that the viva is not always 
viewed as a contributing factor to the assessment process: 'I've even heard examiners say, this is fine, this is a pass, but I want to talk about it' [3, Professor, Pre-1992]. Such behaviour would, however, appear contrary to the QAA recommendation that 'examiners do not normally reveal the outcome to the candidate in advance of the oral exam' (P. 17, Characteristic Statement Doctoral Degrees, QA, 2015). Indeed, the potential risk of adopting such a strategy was recognised given the necessity to verify that the thesis is the student's own work: 'Some examiners are prepared to say at the beginning of the viva, congratulations. I just won't do that anyway because suppose something comes out of the conversation and I thought, Oh hang on, I'm not sure this guy's done the work. OK you're not committed to what you've said earlier but I think it looks a bit unprofessional.' [36, Professor, Pre-1992].

Viva performance, in addition to the written thesis, was viewed by some as contributing to the final outcome of the $\mathrm{PhD}$ assessment: 'The thesis has to be sufficient and the viva has to be sufficient. It's the combination of the two.' [21, Professor, Pre-1992]. However, in the experience of many, the viva provided the opportunity to positively influence the outcome when the thesis itself was something of a disappointment. 'The PhD itself was not very good. It was no thicker than the average pamphlet really. And the student actually delivered a very good defence of this and got it from a pretty near failure to major corrections but a PhD'. [17, Professor, Pre-1992]. In contrast, a poor viva performance does not appear to substantially influence the outcome: 'I literally once had a situation where I thought the student almost talked themselves out of the PhD. On the basis of what was written you had to give the PhD, but in terms of defence, was so bad' [37, Professor, Pre1992].

\section{Responsibility for the selection of PhD examiners}

Approximately $58 \%$ of academic survey respondents indicated that supervisors and students should decide jointly on the external examiner. The remaining $42 \%$ viewed it as the supervisor's decision. Nobody indicated that it was entirely the student's decision. Reflecting on their own experiences, $3 \%$ of recently graduated students said the choice of external examiner was theirs. Approximately $40 \%$ indicated a joint decision, whilst 57\% indicated that the decision was entirely their supervisors. In the follow up interviews, the contribution students could make to examiner selection was 
questioned: 'They [PhD students] rarely come up with anybody that's appropriate or useful' [1, Professor, Post-1992]. Several academics viewed student participation as a courtesy rather than any real input in the external examine selection process: 'You wouldn't dare admit to giving students an input. I let them think of names and half the time it's the same names you've got anyway. I think it is nice to make them feel that you're willing to talk to them, but they clearly can't decide and they have to be told that.' [3, Professor, Pre-1992]. However, consideration was given when students raised an opinion as to who they didn't want: 'In so far [allowing student input] as you wouldn't want to give them their portal enemy [4, Professor, Post-1992]. 'He did ask me who I didn't want as an examiner and there was somebody who I'd met on the conference circuit who had a particular dislike to the paper and I said maybe I don't want her' [6, Recently graduated, Pre-1992]. Other academics, whilst retaining control over the decision, were keen on more active student participation: Trying to make sure they've met and perhaps spent some time with key characters in their gang, so they get a better idea of how those people work. And from those we will then talk about who they would like as their external. And they might say A, and I'll say I'm sorry, I don't think they're good enough for you; or they might say B, and I'll say no, they're a psychopath, you can't trust them. And they'll say C, and well yeah OK, we'll see if C will do it' [7, Professor, Pre-1992]

Irrespective of where responsibility for the decision lies between supervisor and student, external examiner selection requires institutional approval. Institutions are required by the QAA to carefully consider the criteria which they intend to use in appointing examiners (Chapter B11, QAA, 2011). Institutions were found to operate varying guidelines, which in practice results in varying degrees of constraint: 'They get approved by Senate so there's somebody scrutinising who gets appointed and where from. You can use the same external but you can't use them regularly'. [18, Professor, Pre-1992], 'You can't use the same external at this institution within twelve months'. [25, Professor, Pre-1992]. 'You can only use an external roughly about once every five years'. [23, Professor, Pre-1992].

\section{External examiner selection}

According to the QAA, external examiners should have relevant qualifications, experience and understanding of the task (Chapter B11, QAA, 2011). Particular 
interest in the candidate's research topic also features (Characteristic Statement, Doctoral Degrees, QAA, 2015). However, external examiners should not be appointed where there is a conflict of interest, which includes close professional/personal relationships with members of the appointing institution's staff (Chapter B7, QAA, 2011). Given that there is no formal requirement to act as an external examiner, the $\mathrm{PhD}$ assessment process appears to rely on social capital to function. It requires the ability of the academic community to foster trust, cooperation, and shared values among all members (Jackson et al., 2012), in terms of assuring equivalence of standards, through an informal favour exchange. Although rankings of individual institutions, and academics within them, exist at every turn, there is no formal differentiation in the $\mathrm{PhD}$ qualification awarded across UK institutions. This implies that, when it comes to the role of external examining, the accounting and finance community are a homogenous population, across the spectrum of which, social capital could / should exist. Findings with respect to external examiner selection suggest the contrary:

\section{Concentration of viva examining experience}

From the survey, 240 academics indicated their examining experience. Approximately $45 \%$ and $38 \%$ had not acted as external or internal examiner respectively on any occasion. Of those who had examined, the majority had done so on a relatively small number of occasions. Approximately, 31\% and 39\% had acted as external and internal examiner respectively for less than five $\mathrm{PhD}$ students. Widespread experience in $\mathrm{PhD}$ examining appears to be concentrated among relatively few respondents. Approximately $12 \%$ and $8 \%$ respectively had acted as external and internal examiner for over ten students. External and internal examining experience of over 20 students is in the hands of approximately $5 \%$ and $3 \%$ of respondents, respectively. Those with this level of both external and internal examiner experience all hold the position of full professor (with the exception of one respondent who holds the position of reader). In terms of the age profile of those with widespread examining experience (examination of over 10 students), $31 \%$ of external examiners and $47 \%$ of internal examiners are over sixty. Approximately, 57\% of external examiners and $41 \%$ of internal examiners are in their fifties. External examining does not, therefore, appear to be dispersed evenly, and social capital not widely exchanged, across the academic 
community. The viva process appears to be 'too dependent on the small number of people' [24, Recently Graduated, Pre-1992].

\section{Selection of external examiners - academic standing and student calibre}

Academic survey respondents indicated the extent to which they agreed with several statements designed to investigate the selection of examiners. Aggregate responses are shown in Panel A, Table 1 where: $1=$ strongly disagree; 2 = disagree; 3 = neutral; $4=$ agree; and $5=$ strongly agree. On average, respondents refuted the suggestion that $\mathrm{PhD}$ supervisors select examiners who are at an early stage of their career and more easily influenced (mean=2.08). However, a significant number of respondents $(14 \%)$ indicated that they did not know, and a standard deviation of 0.85 indicates a degree of variation among those respondents giving an opinion. Respondents agreed that $\mathrm{PhD}$ supervisors select as high profile an examiner as possible for their $\mathrm{PhD}$ students (mean $=3.43)$. Again, a significant number $(12 \%)$ didn't know and the standard deviation (0.91) was fairly high. Responses were further analysed on the basis of gender, type of institution, length of service and level of internal and external examiner experience (full results available on request). On average, male respondents were in stronger disagreement with the suggestion that $\mathrm{PhD}$ supervisors select examiners who are at an early stage of their career and more easily influenced (mean $=2$ compared with 2.27 for females, $\mathrm{t}=1.92, \mathrm{p}=0.057)$. This was also the case for respondents with higher internal and external examiner experience (those examining 6 or more students). For high external experience, the mean response was 1.83 compared to 2.17 for respondents with less experience $(t=2.70, p=0.008)$. For high internal experience, the mean response was 1.83 compared to 2.15 for respondents with less experience $(t=2.67, p=0.009)$.

\section{[Table 1]}

The influence of academic standing and student calibre on selection was further explored during the interviews. Nearly everything in academic life is graded in more or less subtle ways (Becher \& Trowler, 2001), which would appear to be the case in terms of matching the calibre of examiners and $\mathrm{PhD}$ students on an institutional level. 
From interviews with several distinguished professors, it was clear that they were external examining for students of a similar calibre to their own and they didn't come across students of inferior calibre: 'I suspect there are distinct layers in that market [external examining] and institutions, at a certain level, choose external examiners, who are comfortable with that and it's a bit self-selecting' [2, Professor, Pre-1992]. 'What's going to be visible to me? Who do I act as external examiner for? They'll be good students, they're going to be good, so I see good stuff. I believe there's a degree of self-selection bias here. We know when we have stronger students and weaker students, and we do tailor our external examiners and our internal examiners to the nature of those students' [9, Professor, Pre-1992]. 'When I tend to external examine, it tends to be with institutions and researchers that I know and know of. There are a lot of other institutions that have accounting PhDs, I've seen work in progress which I've been unimpressed with, but I suspect that they get external examiners from institutions of similar calibre' [10, Professor, Pre-1992]. This evidence seems to support Homans (1958) argument, that the less competent approach the more competent less frequently, due to the high costs of repeated admissions of inferiority. The consequence is that 'there are different levels of $\mathrm{PhD}$, there are different academic worlds' [43, Recently Graduated, Pre-1992] as social capital operates across groups of similar types of institutions, leading to cooperation within cliques (Haag and Lagunoff, 2006). By procuring examiners on the basis of their similarities to supervisors and/or from similar institutions, the academic community is indeed segregated and a lack of quality assurance across the population is evident.

In terms of the quality of $\mathrm{PhD}$ work, on average academic survey respondents were neutral in relation to deterioration over time (mean $=3.06$, Panel B, Table 1). However, approximately 19\% of respondents didn't know, and a standard deviation of 1.01 for responses from those expressing an opinion indicates a lack of consensus. Further analysis indicated no significant differences in responses according to gender, type of institution, length of service and level of internal and external examiner experience. In the case of weaker students, several interviewees indicated that they believed that the outcome of the viva could be influenced, and that supervisors would do so, by selecting examiners who could be more easily moulded or influenced: 'I'm sure if you had a weak student people might be inclined to choose soft, for want of a better description, examiners' [Interviewee 11, Professor, Pre-1992 institution]. For 
some, 'Softer' appeared to translate to selecting external examiners of lower ranks: 'If the student is not [good] I would try to choose someone who is more lenient, maybe senior lecturer rather than a professor' [12, Professor, Pre-1992]. Such findings are indicative of examiners being procured on the basis of a favourable $\mathrm{PhD}$ outcome, rather than in the interests of an independent assessment of quality standards. Cooperation in such circumstances appears to rely on the intangible benefits of approval or threats of ostracism accruing to academics of lower standing to supervisors.

However, the selection of examiners who are at an early stage of their career was to be avoided according to the views of several senior academics: 'I do have a rule, I prefer not to use an external examiner who is doing it for the first time, somebody who is relatively recently out of their own PhD. They tend in my experience, to be over picky and over strict. The prickly first time examiner usually is self-confident enough, I think, not to yield to too much pressure'. [2, Professor, Pre-1992]. 'I generally prefer older people. They're easier. Particularly if you've got a questionable one [PhD], you're often on safer ground with someone who is more experienced, because they've seen the range and they know what's involved. Younger people tend to have higher standards, particularly if they're good themselves'. [13, Professor, Pre-1992]. Although the QAA promotes appropriate experience as an external examiner characteristic, it does not rule out early career academics given institutions should consider 'in what circumstances and with what support an inexperienced examiner may be appointed' (Chapter B11, QAA, 2011).

High academic standing / experience of the external examiner was thought to be beneficial in terms of the viva outcome and also to have far reaching potential benefits in terms of the PhD student's future academic career. However, these benefits appear to coincide with student calibre: 'The top academic you can think of in your area, because it will help later on, with a good reference from such external examiner, to get a good job'. [15, Senior Lecturer, Pre-1992]. 'It will also look better on the student's CV later to be examined by some notorious Rottweiler examiner than by some pussycat who is old friends of the supervisor'. [16, Professor, Pre-1992]. The academic standing of the supervisor was also thought to influence the outcome: 'There's almost a reputation effect. So if a particular student was supervised by a 
very big name in an area they'd be more inclined to be passed than if they were supervised by someone who wasn't particularly well known. [11, Professor, Pre1992]. Bourdieu (1986) views social capital as the exclusive property of the elites, created during the process of securing their relative position at the top of the hierarchy. Social capital is used as a means of accessing resources of status and privilege that increases standing, however access to such benefits are unequally distributed (Field, 2010). The implication of this is that students who are supervised by an elite member of the academic community benefit from this reputation halo effect and are potentially more likely to be externally examined by another elite member, reinforcing the social capital exchange of this sub-group of the academic community. As articulated by Field (2010), 'people hand on their networking skills to their children, which then perpetuates inequality throughout the generations' (p.90).

\section{Selection of external examiners - avoidance}

It was widely perceived to be the supervisor's responsibility to discriminate between members of the academic community to avoid external examiners of questionable behaviour: 'I think you are obliged as a PhD supervisor to approach an external who hasn't got any sort of agenda or wants to make a point by flogging the poor PhD student'. [17, Professor, Pre-1992]. 'There are some obnoxious nasty people. There are also some people who are not open to other people's ideas. I mean there are some people who are so unpredictable.' [18, Professor, Pre-1992]. In practical terms, to execute this responsibility, supervisors employ personal knowledge of members of the academic community: 'It's a friend you can trust and a friend will always tell you you're smelly or your shoes don't match. And so if this is a crap PhD, they're going to tell you. And I don't want anybody who wouldn't tell me. At the same time, I want somebody who's going to be straight backed and not play out their own inadequacies.' [7, Professor, Pre-1992]. 'Practically you are selecting examiner's that you have some relationship with and that you know either anecdotally or from experience will most likely come to a favourable view. If we don't know these people it could be risky' [20, Senior Lecturer, Pre-1992]. However, the process of securing an external examiner through a professional/personal relationship with the supervisor, through the action of social capital, is at odds with an external examiner providing an independent peer review. It is also at odds with the QAA requirement of avoiding conflicts of interest. 
The strategy of avoiding the unknown further reinforced a lack of trust across the academic community: 'I am now in the UK for five years or more, nobody ever asks me as external examiner and I know why because people don't know me. People are scared of the unknown'. [21, Professor, Pre-1992]. Evidence of a lack of trust and shared values further reinforces that social capital does not exist across the spectrum of the academic community. In selecting external examiners, supervisors are likely to feel more confident in predicting the behaviour of academics who are similar to themselves rather than try to anticipate the behaviour of academics who are different (Field, 2010; Misztal, 1996). However, if social capital exists only between likeminded members of the academic community, who all know each other, the opportunity to learn is diminished (Field, 2010). In order to successfully contribute to learning and the skill and knowledge development of members of the academic community, social capital needs to exist between diverse others. 'In a fast-changing world, the power of network links to unfamiliar people and organisations is crucial' (Gee, 2002 cited in Field, 2010, p.87).

\section{Selection of external examiners - agreement to act}

It is not only supervisors who fear the unknown. A lack of pre-existing relationships appears to discourage agreement from external examiners to act: 'I typically tend to say no, because I'm not familiar with their process and I'm not familiar with their standards. Because I don't know the supervisors, it means that the vet on the candidate's work is pretty much, you know, a longer shot bet'. [22, Professor, Pre1992]. 'Of those that I do get asked to do, I probably turn down well over half, because I have to trust and know the supervisor.' [7, Professor, Pre-1992].

The lack of financial incentive to act as external examiner was viewed as a further problem: 'Being an external examiner is a terribly under-rewarded job. They pay next to peanuts. I worked out I could make that in ten minutes doing consulting, and I read a whole thesis for that, and do questions, write a report.' [16, Professor Pre-1992]. This appears to reinforce the view that informal favour exchange is central. The process relies on generating goodwill and the opportunity for reciprocity: 'This is all a greatest favour it's not an economic relationship at all'. [7, Professor Pre-1992]. It's because we know we've both got to get externals and one way of doing it is to generate goodwill by doing it for them.' [16, Professor Pre-1992] 
Those interviewed also directly raised concerns over existing personal relationships between supervisors and examiners in terms of the objectivity and fairness of the viva process: 'I've done one of yours and you do one of mine, and therefore outcomes are not always determined by the level of scrutiny but by, you know, more complex relationships between the supervisor and the choice of examiner'. [22, Professor, Pre1992]. However, external examiner choice based on personal relationships potentially occurs across groups of academics rather than on a one-to-one basis: 'It's the case of in the population of limited people, you need someone to do you a favour and so you do them a favour, but it won't be one to one, it'll be around a circle of people'. [3, Professor, Pre-1992]. The outcome being 'small groups of faculty who, perhaps for good and bad reasons, examine each other's students in small networks'. [24, Recently Graduated, Pre-1992].

\section{Pressure in relation to $\mathrm{PhD}$ outcomes}

\section{Who determines PhD outcome?}

Once the external examiner has been selected, it was widely acknowledged that the outcome of the viva is predominantly their domain: 'You're the external examiner so actually you have power. It's your call at the end of the day, the casting vote.' [18, Professor, Pre-1992]. 'The presumption here is that the external is king. The criteria is contribution to knowledge which is like beauty in the eye of the beholder'. [23, Professor, Pre-1992]. Further, where disagreement existed between examiners, interviewees were of the view that internal examiners did not usually have their way: 'It's often the external examiner who is the most draconian, if push comes to shove, the external examiner carries the sway.' [2, Professor, Pre-1992].

\section{Potential pressures on examiners}

On average, survey respondents disagreed with both the suggestion that $\mathrm{PhD}$ supervisors exert pressure on examiners to pass $\mathrm{PhD}$ students (mean=2.51, Panel $\mathrm{C}$, Table 1) and that examiners feel pressure in relation to disappointing students by requiring resubmission and not awarding the $\mathrm{PhD}$ at the viva (mean=2.86, Panel $\mathrm{C}$, Table 1). However, the latter mean response was statistically significantly different 
from neutral at only the $10 \%$ confidence level. Standard deviations of 1.00 and 1.12 respectively indicate a lack of consensus amongst respondents expressing a view. Further, $14 \%$ indicated that they didn't know whether PhD supervisors exert pressure on examiners to pass $\mathrm{PhD}$ students and $16 \%$ didn't know whether examiners feel pressure in relation to disappointing students by requiring resubmission and not awarding the $\mathrm{PhD}$ at the viva. Further analysis indicated no significant differences in responses according to gender, type of institution, length of service and level of internal and external examiner experience.

In general, interviewees did not claim to experience pressure from supervisors for a favourable viva outcome. However, some examiners clearly do feel pressure in terms of how the outcome could potentially impact the student: 'The penalty in terms of what it may or may not delay in terms of jobs, visas etc., then those considerations, you know, I think are taken on board.' [25, Professor, Pre-1992]. Others appear to be focused exclusively on the contribution to the discipline: 'You don't say 'Oh this person has got to get their PhD, they're desperate, so never mind what rubbish they've written', you have got to think ultimately about the subject matter'. [16, Professor, Pre-1992]. Although external examiners attempted to minimise pressure by adopting a risk-averse strategy in terms of accepting an appointment, it wasn't always successful:

'The personal pressure in that you never want to see this bloody thing again. I've had a couple of occasions where I've had to fight that. What had transpired had been that the supervisor I thought I knew and respected has put in nothing, nothing to do with it, and they're just sitting there, letting it all happen around them. I resent deeply that I have to put in several days' work to salvage a PhD, when the supervisor should have done it'. [Interviewee 7, Professor, Pre-1992 institution]

\section{Summary and Conclusions}

Based on survey and interview evidence across the UK accounting and finance academic community, the present paper investigates the role of the viva in the $\mathrm{PhD}$ assessment process and the selection of external examiners. The fundamental premise 
of external examining is that it is an independent peer assessment process to ensure quality standards. However, in the absence of any formal requirement for academics to act as external examiners, external examiner procurement and the viva process relies on social capital to function, and the notion of independence becomes questionable. The use of an external examiner acquired through the social capital of the $\mathrm{PhD}$ supervisor thus creates somewhat of a paradox, by potentially increasing the subjectivity of the $\mathrm{PhD}$ assessment process, rather than fulfilling the objective function of quality assurance.

The evidence suggests that the viva has multiple roles. A verification role regarding both plagiarism and substantial supervisor involvement was identified, which appears to support the notion of an independent peer review, quality assurance, and a gatekeeping function (Morley et al., 2003). Despite the UK Quality Code for Higher Education making it clear that $\mathrm{PhD}$ assessment is based on both the thesis and the viva (Chapter B11, QAA, 2011), the role the viva plays in determining the outcome was found to be diverse. Several academics viewed the written thesis as the primary focus; and whilst the thesis and viva performance were both viewed by others as contributing to the final outcome, the viva seemed to contribute only in a favourable manner. Poor viva performance did not appear to substantially influence the outcome, which appears somewhat contrary to the role of verification in terms of substantial supervisor involvement, quality assurance, and the gatekeeping function.

Student input to the selection of an external examiner varied. However, where students expressed a view as to who they did not want, this was given serious consideration. Student input could be perceived as further undermining external examiner independence and the viva's gatekeeping function. The extent to which the decision lay with the supervisor (and/or student) is theoretically governed by institutional guidelines on external examiner appointments. Findings indicated great variation which in reality resulted in varying degrees of constraint. Widespread experience in $\mathrm{PhD}$ examining was concentrated among relatively few senior academics, indicating that social capital is not widely exchanged across the academic community. Further, very few academics below the age of 50 had substantial experience of external or internal examining. Although experience is expected, to some extent, to be commensurate with age and career duration, the concentration of 
experience amongst those near to retirement age is cause for concern. The situation is further exacerbated since these senior academics believe that the selection of $\mathrm{PhD}$ examiners from those at early stages of their career is to be avoided. This evidence of a lack of trust further reinforces that social capital does not exist across the spectrum of the academic community.

The desired outcome of the viva drove examiner selection. The calibre of examiners and $\mathrm{PhD}$ students are matched on an institutional level, indicating that social capital operates across groups of similar institutions. The academic community is thus segregated and quality assurance across the population is not achieved through the external examiner system. For weaker students, supervisors selected examiners who could be more easily moulded or influenced, perhaps occupying middle ranks. Early career examiners were thought to be self-confident enough not to yield to pressure which, accompanied with their higher set of expectations, should be avoided. These findings indicate that the external examiner function can be used to provide favourable outcomes for supervisor/student, and that this function in some cases takes precedence over an independent assessment of quality standards. Further, cooperation appears to rely on the intangible benefits of approval / threats of ostracism between academics of senior and middle ranks.

In the case of strong students, supervisors selected examiners of high academic standing / experience with the aim of enhancing the student's future academic career. It was apparent that, through the selection of $\mathrm{PhD}$ examiners, supervisors of high academic standing had the power to contribute to the creation and maintenance of elites and the marking down of those who are not among the front runners of the discipline (Bourdieu, 1986; Becher \& Towler, 2001). Supervisors also took responsibility for avoiding external examiners whose behaviour they perceived as questionable and/or who did not share the same values. Therefore, social capital exists primarily between like-minded members of the community, limiting the knowledge development which could be achieved by the development of social capital between diverse others. As a consequence, the academy is fragmented into groups of likeminded academics across the spectrum of institutions, abilities and agendas. Whilst a shared understanding can broadly exist within these groups, it is absent across groups, creating inconsistencies in the $\mathrm{PhD}$ assessment process across the academy. 
The matching of external examiners to $\mathrm{PhD}$ students required supervisors to employ personal knowledge of members of the academic community, along with the strategy of avoiding the unknown. Several respondents highlighted that the choice of external examiner based on personal relationships occurred across groups of academics rather than on a one-to-one basis. However, personal relationships between supervisors and external examiners are at odds with an independent peer review and at odds with quality assurance requirements of avoiding conflicts of interest. The academic community, as a result, is characterised by several homogenous sub-groups which preclude social capital in action across the entire population, exhibits cooperation within cliques (Haag \& Lagunoff, 2006), and potentially creates varying standards of quality.

The viva outcome is predominantly the external examiner's decision. Problems, in terms of the supply of external examiners, arose from the pre-requisite of knowing and trusting the supervisor, and from the lack of financial incentive. The existence of social capital within sub-groups rather than across the entire academic community thus has an adverse impact on external examiner supply. Once selected, the external examiners who were interviewed did not experience pressure from supervisors for a favourable outcome. However, the primary motivation across external examiners was somewhat inconsistent. Whilst some examiners are exclusively focused on the contribution of the $\mathrm{PhD}$ work to the discipline, others feel pressure in terms of how the outcome could impact the student with respect to, for example, visa requirements and employment prospects. Further work for the external examiner, arising from unfavourable viva outcomes, can increase such pressure.

In the current climate, there is no doubt that the need for successful $\mathrm{PhD}$ completions exerts pressure on academics in both the roles of supervising and examining. The evidence provided in the present paper suggests that supervisors select examiners with the outcome firmly in mind. An independent peer review cannot be said to be achieved, when supervisors use the social capital which exists within their own subgroup of the academic community in making their choice. The $\mathrm{PhD}$ assessment process itself appears to provide a vehicle for reinforcing social capital within subgroups, described cynically as a form of 'back scratching and self-advancement' (Field, 2010, p.84); and sub-groups of the academic community grow as PhD students 
are admitted. Supervisors and examiners together appear to gate-keep the discipline, not in its entirety but within cliques. Consequently, at the viva stage, students are rarely turned away. Although it was widely cited that verification was an important role of the viva, in particular in terms of the $\mathrm{PhD}$ thesis not being the supervisor's work, the system falls down when a poor viva performance has little influence on the outcome. In short, the underlying function of external examining in $\mathrm{PhD}$ assessment is undermined by the action of social capital, despite the existence of a regulatory framework for research degrees in the UK.

The findings in the present paper have policy implications. The academy and institutional management should question the merits and the quality implications of using the quantity of $\mathrm{PhD}$ admissions and completions as a performance indicator, since this creates the potential for adverse unintended consequences. Institutions and the academy could introduce formal requirements to act, and offer subsequent support to encourage academics to act as external examiners, thus reducing the system's reliance on informal favour exchange and enhancing independence. An increase in the benefits associated with external examiner appointment, in the form of institutions awarding hours for external citizenship and financial compensation which reflects the time and responsibility associated with the task, has the potential to increase external examiner supply. Rather than individual institutional guidelines on external examiner appointments which result in varying degrees of constraint, national/supranational guidelines could further enhance independence and promote consistency in terms of who can examine (also who can supervise). In terms of consistency and quality assurance, the academy should address the issue of developing shared understandings of both the role of the viva in the assessment process and the minimum quality threshold for a $\mathrm{PhD}$ to be awarded. The outcome categories of the $\mathrm{PhD}$ assessment process should be standardised across the academy. PhD supervision development and training has come into focus through recent policy developments across the higher education sector. For example, Research Councils UK (RCUK) have highlighted the need for institutions to demonstrate that their $\mathrm{PhD}$ supervisors are developed and supported in order to qualify for funding through doctoral training partnerships. The findings in the present paper support expanding this need to include the training of, and support for, external examiners. In the absence of pressures for successful $\mathrm{PhD}$ completions being removed, and/or the introduction of academy-wide 
standards / requirements on external examiner appointment to reduce the reliance on social capital, the $\mathrm{PhD}$ assessment process appears problematic. It provides opportunity for the development of rogue cliques in the academic community driven by favourable outcomes in terms of personal benefits and costs and accompanied by the consequence of new entrants of insufficient quality.

As with all research, there are several limitations with the present study. The first limitation relates to the sample representativeness. While the database of academic staff, from which survey evidence and follow up interviews were initiated, was considered to represent the entire population, difficulties experienced in tracing recently graduated $\mathrm{PhD}$ students has introduced a bias in favour of recently graduated $\mathrm{PhD}$ students currently employed in UK institutions. Further, interview participation by academic staff is somewhat biased in favour of those holding senior ranks. The second potential limitation relates to the institutional setting of the study where accounting and finance exist together as academic units, and consequently findings do not attempt to separate these subject areas. It must be recognised, however, that each of these subject areas has distinct features, potentially introducing differences in relation to the issues explored in the present paper. A third potential limitation arises from the fact that the researchers themselves are part of the academic community being investigated. Whilst every effort has been made to conduct the research with an objective mindset, the relationship of the researchers as participants in the activities being studied is acknowledged. In addition to further research to address the bias in survey respondents contained in the present study, future research should seek to investigate the extent to which the $\mathrm{PhD}$ assessment process is systematically failing to identify those $\mathrm{PhD}$ students which do not meet the minimum quality threshold. The causes and consequences of these cases, together with the identification of moderating factors, also requires further systematic investigation, across a range of country and discipline settings. 


\section{References}

Araujo, E. R. (2005). Understanding the $\mathrm{PhD}$ as a phase in time. Time \& Society, 14(2/3), 191-211.

Barash, D. (2003). The survival game: How game theory explains the biology of cooperation and competition, New York: Holt.

Beattie, V. \& Smith, S.J. (2012). Today's Ph.D. students - Is there a future generation of accounting academics or are they a dying breed? A UK Perspective. ICAS Report. Edinburgh: Institute of Chartered Accountants of Scotland.

Becher, T. \& Trowler, P.R. (2001). Academic Tribes and Territories, second edition. The Society for Research into Higher Education.

Bloxham, S., Hudson, J., den Outer, J. \& Price, M. (2015). External peer review of assessment: an effective approach to verifying standards? Higher Education Research \& Development, 34(6), 1069-1082.

Bloxham, S. \& Price, M. (2015). External examining: fit for purpose? Studies in Higher Education, 40(2), 195-211.

Bourdieu, P. (1986). The forms of capital, in J.G. Richardson (ed.), Handbook of Theory and Research for the Sociology of Education, New York, Greenwood Press.

Breimer, L.H. \& Nilsson, T.K. (2014). Considerations for appointing an external examiner of a $\mathrm{PhD}$ in the biomedical sciences in Sweden: A questionnairebased survey. Scientometrics, 98, 2039-2049.

Carter, S. (2008). Examining the doctoral thesis: a discussion. Innovations in Education and Teaching International, 45(4), 365-374.

Casanueva, C. \& Larrinaga, C. (2013). The (uncertain) invisible college of Spanish accounting scholars. Critical Perspectives on Accounting, 24(1), 19-31.

Clarke, G. (2013). Developments in doctoral assessment in the UK. Chapter 3 in Komp,M. and Denicolo, P. Critical Issues in Higher Education, Critical Issues in the Future of Learning and Teaching (8), Sense Publishers.

Cole, S. (1983). The hierarchy of the sciences. American Journal of Sociology, 89(1), 111-139.

Coleman, J.S. (1988). Social Capital in the Creation of Human Capital. American Journal of Sociology 94 Supplement: Organizations and Institutions: Sociological and Economic Approaches to the Analysis of Social Structures, 95-120.

Crossouard, B. (2011), The doctoral viva voce as a cultural practice: the gendered production of academic subjects. Gender and Education, 23(3). 313-329. 
Denicolo, P. (2003). Assessing the PhD: a constructive view of criteria. Quality Assurance in Education, 11(2), 84-91.

ESRC (2009). Postgraduate Training and Development Guidelines 2009. Swindon. Economic and Social Research Council.

Feinberg, Y. \& Kets, W. (2014). Ranking Friends. Journal of Economic Behaviour \& Organization, 107 Part A, 1-9.

Field, J. (2010). Social Capital second edition. Routledge.

Gibney, E. (2013). Whim and rigour, Times Higher Education 25 April, 34-38.

Green, H. (2008). United Kingdom. Chapter 2 in 'Towards a Global PhD? Forces and Forms in Doctoral Educatio Worldwide'. Edited by Nerad and Heggulund, University of Washington Press.

Haag, M. \& Lagunoff, R. (2006). Social norms, local interaction, and neighbourhood planning. International Economic Review, 47(1), 265-296.

Hannan, A. \& Silver, H. (2006). On being an external examiner. Studies in Higher Education, 31(1), 57-69.

Homans, G.C. (1958). Social Behaviour as Exchange. American Journal of Sociology, 63, 597-606.

Jackson, C. \& Tinkler, P. (2001). Back to basics: a consideration of the purposes of the PhD viva. Assessment and Evaluation in Higher Education, 26(4), 355366.

Jackson, M.O., Rodriguez-Barraquer, T. \& Tan, X. (2012). Social Capital and Social Quilts: Network Patterns of Favour Exchange. American Economic Review, 102(5), 1857-1897.

Khalifa, R. \& Quattrone, P. (2008). The governance of accounting academic: Issues for debate. European Accounting Review, 17(1), 65-86.

Kyvik, S. (2014). Assessment procedures of Norwegian $\mathrm{PhD}$ theses as viewed by examiners from the USA, the UK and Sweden. Assessment and Evaluation in Higher Education, 39(2), 140-153.

Locke, W. \& Bennion, A. (2013). Satisfaction in stages: the academic profession in the United Kingdom and the British Commonwealth - career stages and trajectorie. In Bentley, P.J., Coates, H., Dobson, I.R., Goedegebuure, L. \& Meek, V.L. (Eds.), Job Satisfaction Around the Academic World, Springer, Dordrecht: The Netherlands, 223-238.

Loumansky, A. \& Jackson, S. (2004). Out of the frying pan into the viva. Journal of International Women's Studies, 5(3), 22-32. 
Misztal, B.A. (1996). Trust in Modern Societies, The Search for the Bases of Social Order. Polity Press Cambridge.

Morley, L., Leonard, D. \& David, M. (2002). Variations in vivas: Quality and equality in British $\mathrm{PhD}$ assessment. Studies in Higher Education, 27(3), 263-273.

Morley, L., Leonard, D. \& David, M. (2003). Quality and equality in British PhD assessment. Quality Assurance in Education, 11(2), 64-72.

Park, C. (2003). Levelling the playing field: towards best practice in the doctoral viva. Higher Education Review, 36(1), 47-67.

Parker, L. \& Guthrie, J. (2010). Business schools in the age of globalisation. Accounting, Auditing \& Accountability Journal, 23(1), 5-13.

Phillips, E.M. Quality in the PhD. Points at which quality may be assessed. Chapter 7 of Burgess, R.G. (ed.). (1994). Postgraduate Education and Training in the Social Sciences: Processes and Products. London: Jessica Kingsley Publishers Ltd.

Powell, S. \& Green, H. (2007). The Doctorate Worldwide. The Society for Research into Higher Education. Open University Press.

Putman, R.D. (1995). Tuning in, tuning out: the strange disappearance of social capital in America. Political Science and Politics, 28, 1-20.

QAA (2008). The Framework for Higher Education Qualifications in England, Wales and Northern Ireland, $2^{\text {nd }}$ edition, August, Mansfield Quality Assurance Agency for Higher Education.

QAA (2014). Doctoral Degree Characteristics. Draft for consultation December 2014. http://www.qaa.ac.uk/en/Publications/Documents/Doctoral-DegreeCharacteristics.pdf (accessed 20 July 2015)

Smith, S.J. \& Urquhart, V. (2016). Accounting and Finance Academics in UK Universities: Evaluating a Changing Landscape. Working paper.

Twale, D.J. \& De Luca, B.M. (2008). Faculty incivility. The rise of the academic bully culture and what to do about it. John Wiley \& Sons, inc.

Wallace, S. (2003). Figuratively speaking: Six accounts of the $\mathrm{PhD}$ viva. Quality Assurance in Education, 11(2), 100-108.

Wellington, J. (2010). Supporting students' preparation for the viva: their preconceptions and implications for practice. Teaching in Higher Education, 15(1),71-84. 
Whitley, R. (1984). The Intellectual and Social Organization of the Sciences. Oxford: Clarendon Press. 
Table 1: Questionnaire views of academic staff

\section{Panel A: External Examiner Selection}

\begin{tabular}{|l|c|c|c|c|c|}
\hline $\begin{array}{l}\text { Question: To what } \\
\text { extent do you agree } \\
\text { with the following } \\
\text { statements? }\end{array}$ & n & Median & Mean ${ }^{\mathbf{1}}$ & $\begin{array}{l}\text { Sig difference } \\
\text { from neutral }\end{array}$ & $\begin{array}{c}\text { Standard } \\
\text { Deviation }\end{array}$ \\
\hline $\begin{array}{l}\text { PhD supervisors } \\
\text { select as high profile } \\
\text { examiner as possible } \\
\text { for their PhD students }\end{array}$ & 201 & 4 & 3.43 & $\begin{array}{c}\mathrm{t}=6.67 \\
\mathrm{p}=0.000^{* * *}\end{array}$ & 0.91 \\
\hline $\begin{array}{l}\text { PhD supervisors } \\
\text { select examiners who } \\
\text { are at an early stage of } \\
\text { career and more easily } \\
\text { influenced }\end{array}$ & 198 & 2 & 2.08 & $\begin{array}{c}\mathrm{t}=-15.30 \\
\mathrm{p}=0.000^{* * *}\end{array}$ & 0.85 \\
\hline
\end{tabular}

\section{Panel B: Deterioration of PhD Thesis Quality}

\begin{tabular}{|l|c|c|c|c|c|}
\hline $\begin{array}{l}\text { Question: To what } \\
\text { extent do you agree } \\
\text { with the following } \\
\text { statements? }\end{array}$ & n & Median & Mean $^{1}$ & $\begin{array}{c}\text { Sig difference } \\
\text { from neutral }\end{array}$ & $\begin{array}{c}\text { Standard } \\
\text { Deviation }^{\text {Trom }}\end{array}$ \\
\hline $\begin{array}{l}\text { The quality of the } \\
\text { PhD thesis has } \\
\text { deteriorated over time }\end{array}$ & 186 & 3 & 3.02 & $\begin{array}{c}\mathrm{t}=0.22 \mathrm{p}= \\
0.827\end{array}$ & 1.01 \\
\hline
\end{tabular}

\section{Panel C: Pressure on External Examiners}

\begin{tabular}{|l|c|c|c|c|c|}
\hline $\begin{array}{l}\text { Question: To what } \\
\text { extent do you agree } \\
\text { with the following } \\
\text { statements? }\end{array}$ & $\mathbf{n}$ & Median & Mean $^{\mathbf{1}}$ & $\begin{array}{l}\text { Sig difference } \\
\text { from neutral }\end{array}$ & $\begin{array}{l}\text { Standard } \\
\text { Deviation }\end{array}$ \\
\hline $\begin{array}{l}\text { Examiners feel } \\
\text { pressure in relation to } \\
\text { disappointing students } \\
\text { by requiring } \\
\text { resubmission and not } \\
\text { awarding the degree } \\
\text { at the viva }\end{array}$ & 191 & 3 & 2.86 & $\begin{array}{c}\mathrm{t}=-1.69 \\
\mathrm{p}=0.093^{*}\end{array}$ & 1.12 \\
\hline $\begin{array}{l}\text { PhD supervisors exert } \\
\text { pressure on examiners } \\
\text { to pass PhD students }\end{array}$ & 201 & 2 & 2.51 & $\begin{array}{c}\mathrm{t}=-6.98 \\
\mathrm{p}=0.000^{* * *}\end{array}$ & 1.00 \\
\hline
\end{tabular}

Notes to table:

1. Response categories are: 1-strongly disagree, 2-disagree, 3-neutral, 4-agree, 5-strongly agree

2. Significantly different from neutral (3) at $10 \%(*), 5 \%(* *)$ and $1 \%$ level $(* * *)$ using two-tailed t-test. Comparable results were obtained using the nonparametric 1-sample Wilcoxon test. 